\title{
Combined-modality Therapy for Locally Advanced Esophageal Cancer in Endemic Region of Turkey: A Single-Center Multimodal Experience
}

\author{
Hamit Başaran ${ }^{1,2,}$, Deniz Arslan ${ }^{1,3}$, Okan özdemir ${ }^{1}$, Menekșe Turna ${ }^{1}$, Yılmaz Özdemir ${ }^{1}$, Sibel Karaca ${ }^{1,4}$ and Asuman \\ Önol Mirik ${ }^{5}$ \\ ${ }^{1}$ Health Science University, Regional Training and Research Hospital, Department of Radiation Oncology, Erzurum, Turkey \\ 2 Department of Radiation Oncology, Faculty of Medicine, Selcuk University, Konya, Turkey \\ 3 Biruni University, Medical Faculty Hospital, İstanbul, Turkey \\ ${ }^{4}$ Department of Radiation Oncology, Faculty of Medicine, Akdeniz University, Antalya, Turkey \\ 5 Tekirdag State Hospital, Tekirdag, Turkey \\ * Corresponding author: Hamit Başaran, Department of Radiation Oncology, Faculty of Medicine, Selcuk University, Konya, Turkey. Tel: \\ +903322244080; Email: drhbasaran@gmail.com
}

Received 2020 December 12; Revised 2021 February 03; Accepted 2021 February 19.

\begin{abstract}
Background: Esophageal cancer (EC) is known as the most common cancer around the world. The evidence supports that preoperative chemoradiotherapy (CRT) improves resectability and survival in locally advanced EC patients.

Objectives: The current study aimed to evaluate the results of treatment in patients suffering from EC in an endemic region.

Methods: In this study, a total of 180 EC patients treated with curative radiotherapy (RT) were retrospectively evaluated. Primary tumor location, histopathological characteristics, tumor, nodes, and metastases (TNM) status, gender, age, treatment modalities, and survival period were also assessed. The effects of prognostic factors on the survival rate were evaluated using single variable analysis.

Results: The median time of follow-up was reported as 22.9 months (range: 6-115 months). After 1-, 3-, and 5-year follow-up, the rates of survival were calculated at $86.6 \%, 46.6 \%$, and $32.5 \%$, respectively. The present study was conducted on $77(42.8 \%)$ male and 103 $(57.2 \%)$ female patients (mean age: $60 \pm 12$ years). In histopathological assessment, squamous cell carcinoma was the most frequent diagnosis ( $\mathrm{n}=156 ;-86.6 \%)$. The clinical stages were reported as II in $36.6 \%(\mathrm{n}=66)$, IIIa in $23.4 \%(\mathrm{n}=42)$, IIIb in $15.5 \%$ ( $\mathrm{n}=28$ ), and IIIc in $24.5 \%(\mathrm{n}=44)$ of the patients. In this study, $54(25 \%)$ patients were treated with definitive RT, 33 patients $(18.3 \%)$ with postoperative adjuvant CRT or RT, 59 patients (32.8\%) with preoperative CRT or RT, and 43 patients $(23.9 \%)$ with definitive CRT. The Eastern Cooperative Oncology Group (ECOG) performance status was observed to be ECOG 0 in 51 subjects (28.4\%), ECOG 1 in 95 subjects (52.8\%), and ECOG 2 in 34 subjects (18.8\%). Moreover, 96 (53.4\%) and $84(46.6 \%)$ patients received conventional and conformal RT, respectively. The median time of overall survival (OS) was reported as 29 months. In univariate analysis, the T stage $(\mathrm{P}=0.041), \mathrm{N}$ stage $(\mathrm{P}=0.033)$, TNM staging $(\mathrm{P}=0.00)$, and concomitant CRT $(0.001)$ were prognostic factors affecting median OS time. Concomitant CRT (hazard ratio [HR]: 0.513; 95\% CI: 0.337-0.779; P=0.002) and TNM stage (HR: 2.265; 95\% CI: 1.409-3.641) were observed statistically significant as independent prognostic factors of mortality in multivariate analysis.

Conclusion: Long-term survival using combined-modality therapy was demonstrated in patients with locally advanced EC. Furthermore, based on the results of multivariate analysis, TNM stage and concomitant CRT were considered independent prognostic factors of mortality.
\end{abstract}

Keywords: Chemoradiotherapy, Esophageal cancer, Prognosis, Survival

\section{Background}

Esophageal cancer (EC) is known as the eighth common cancer around the world. It is estimated that 17,650 cases will be diagnosed in the United States in 2019 , and approximately 16,080 mortalities are expected to occur in the United States due to this disease (1). Based on 2018 global cancer statistics, 572,032 new EC cases (3.2\% of all cancers) and 508,585 cases of EC-related mortalities $(5.3 \%$ of all cancers) were reported worldwide (2). The EC has two major histological types, namely esophageal squamous cell carcinoma (ESCC) and esophageal adenocarcinoma (EAC). Worldwide, more than 90\% of the cases are reported by ESCC and EAC (3). Despite an increase in obesity and gastroesophageal reflux disease (GERD), there is a decrease in the incidence of ESCC; however, an increase in the incidence of EAC is observed, especially in western countries $(4,5)$.

Although the etiopathogenesis is not completely clear, GERD, obesity, diet, smoking, and Helicobacter pylori infection have been mentioned in the etiopathogenesis of upper gastrointestinal (GI) tract tumors. According to the results of a study carried out by Koca et al., smoking, hot tea, and insufficient consumption of fruits and vegetables have been determined to be the risk factors in the etiology of EC in the Anatolian region of Turkey that is endemic for upper GI tract tumors (6).

Epidemiological studies on estrogen exposure in EC showed the difference in the incidence of this condition based on gender (7). The EC is more prevalent in the sixth and seventh decades of life. The EC is one of the most lethal tumors among GI tract tumors and approximately $50 \%$ to $60 \%$ of patients are diagnosed at the metastatic period or locally advanced stage regardless of histopathological 
differences worldwide $(8,9)$. However, preoperative or definitive concurrent chemoradiotherapy (CRT) is the gold standard for locally advanced EC patients diagnosed at the curable stage.

According to the National Practice Guidelines for Clinical Practice (NCCN 02.2019 version), preoperative CRT is recommended with level I of evidence; nevertheless, there has been no prospective randomized trial on induction chemotherapy (CT) before CRT (10-12). Furthermore, there have been no data to support adjuvant CT after preoperative CRT and the benefit of neoadjuvant CT seems to be limited to EAC. Definitive radiotherapy (RT) is never a curative treatment and is used in palliation (3). On the other hand, preoperative CRT in locally advanced EC patients increased complete resection (R0) rates in responsive patients (13). The effect of preoperative CRT on patients with early-stage EC has been investigated in previous studies (14).

Finally, the evidence supports that preoperative CRT improves resectability and survival in locally advanced EC patients.

\section{Objectives}

The current study aimed to evaluate the results of treatment in patients suffering from EC in the Anatolian region of Turkey as an endemic region.

\section{Methods}

In this study, 180 patients diagnosed and treated with EC within May 2007 to September 2016 in Erzurum Regional Training and Research Hospital in Erzurum, Turkey, were retrospectively evaluated (Table 1). The inclusion criteria of the present study were the subjects with a pathologic diagnosis of EC, nonmetastatic disease, Eastern Cooperative Oncology Group (ECOG) performance status within 0 and 2, and patients scheduled for curative treatment. The study subjects were primarily evaluated for oncological surgery clinic and definitive CRT was recommended to patients considered to be inoperable. Neoadjuvant CRT decisions are made in multidisciplinary councils with the cooperation of medical oncologists, radiation oncologists, and oncological surgeons.

While considering the treatment, patients' performance status and treatment acceptance status were all under consideration. For all the patients, curative treatment results, survival analysis, age distribution, gender, location of the primary tumor, histopathological characteristics, tumor, nodes, and metastases (TNM) staging, and oncological treatment modalities were recorded. The effect of prognostic factors on survival was investigated using univariate analysis. The patients' data were obtained by specialists from file reviews and electronic data banks. Some information was also obtained from the

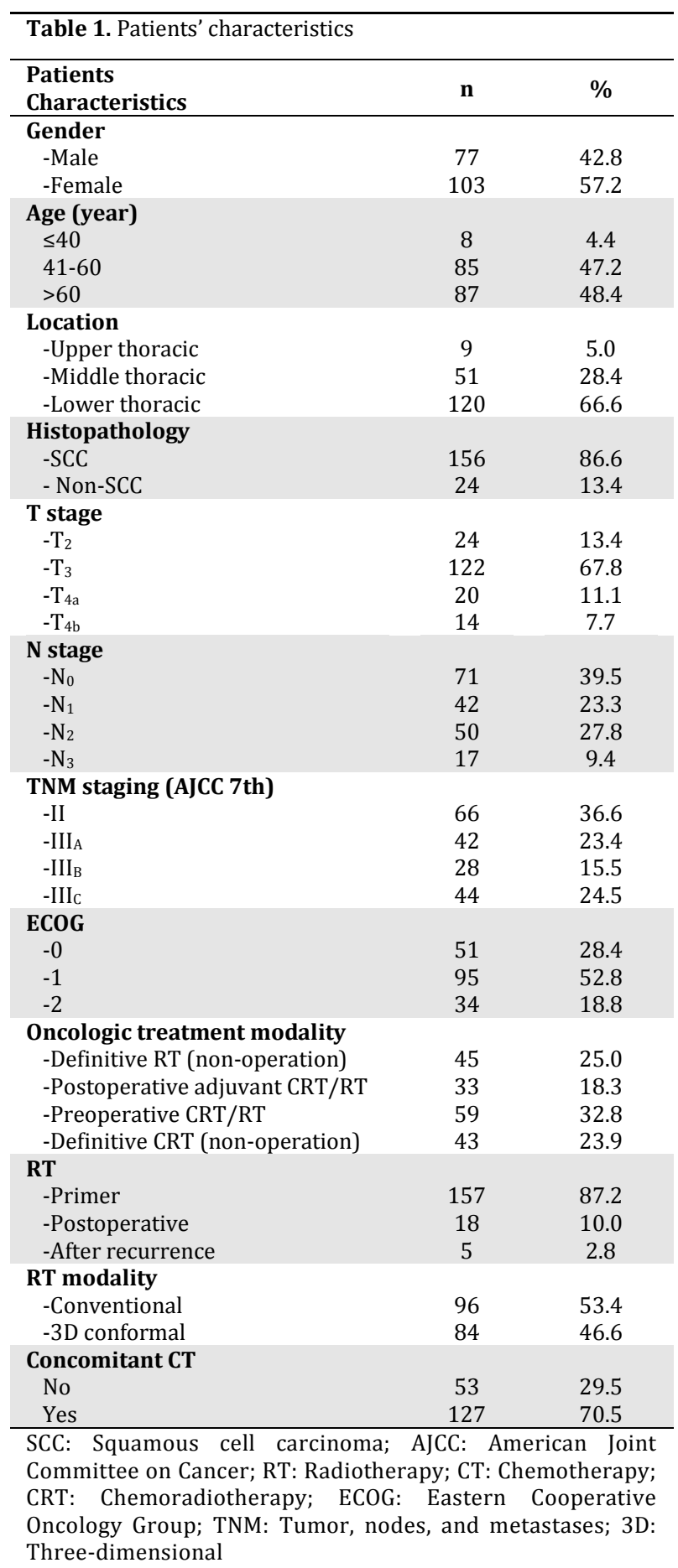

patients and their relatives. The staging was also made possible using the 7 th edition of the American Joint Committee on Cancer (AJCC) published in 2010.

\subsection{Ethics statement}

The ethical approval of this retrospective singlecenter study was obtained by the ethics committees of Health Science University Regional Training and Research Hospital in Erzurum, Turkey. The study procedures were performed under the ethical principles of the Institutional and/or National Research Committee and in accordance with the 
1964 Helsinki Declaration and its later amendments or comparable ethical standards. All the study subjects gave informed consent.

\subsection{Treatment procedures}

The RT planning in 97 patients (53.6\%) was carried out using Cobalt-60 teletherapy apparatus (Theratron Brand, Elite 80 Model, MDS Nordion, Ottawa, Canada) and two-dimensional (2D) conventional radiation beam. The RT in 84 patients (46.4\%) was planned and executed with a linear accelerator device (Elekta Brand, Synergi Model, CMS, XIO, Stockholm, Sweden) using three-dimensional (3D) conformal dose distribution. The patients underwent radiation treatment for 5 weeks (5 days per week) at 1.8-2 Gy/day with a total radiation dose of 45-50.4 Gy/25-28 fractions simultaneously with CT.

The definition of the tumor and target volumes for irradiation consisted of only the primary tumor with a $5 \mathrm{~cm}$ superior and inferior margin in 2D conventional planning, $3 \mathrm{~cm}$ in 3D conformal planning, and $2 \mathrm{~cm}$ lateral margin in both plans. The RT was applied using anterior-posterior fields as opposed to conventional and multiple fields in 3D conformal planning (15). Concurrent CRT was used in 102 patients (56.4\%). The most commonly used CT protocol was the carboplatin plus paclitaxel regimen.

Descriptive statistics were expressed as frequencies and percentages for the categorical data. The Kaplan-Meier method was utilized in order to analyze the survival rate. The log-rank test was employed for comparative survival analysis. The univariate analysis caused the identification of independent prognostic factors using Cox regression analysis for variables with a statistically significant difference under $10 \%$, type-1 error. SPSS software (version 20.0) was used for statistical analysis. All the tests were bi-directional and univariate analysis was considered to be statistically significant in case of a pvalue of less than 0.05 .

\section{Results}

Table 1 tabulates a summary of the patients' demographics. The present study was carried out on patients with a mean age of $60 \pm 12$ years. When the study subjects were grouped based on their age, 4.4\% $(n=8), 47.2 \%(n=85)$, and $48.4 \%(n=87)$ of them were 40 years or younger, within the age range of 40-60 years, and 60 or older, respectively. The median duration of follow-up was 22.9 months (range: 6-115 months). At the end of follow-up, 91 patients (50.5\%) survived. The median time of overall survival (OS) in the present study was 29 months (standard error [SE]: 4.859; 95\% confidence interval [CI]: 19.47738.523; Figure 1). In addition, 1-, 3-, and 5-year survival rates were reported as $86.6 \%, 46.6 \%$, and $32.5 \%$, respectively.

The distribution of the patients receiving treatment according to AJCC 2010 staging system at the time of diagnosis included T2 $(n=24 ; 13.4 \%)$, T3 $(\mathrm{n}=122 ; 67.8 \%)$, T4a $(\mathrm{n}=20 ; 711.1 \%)$, and $\mathrm{T} 4 \mathrm{~b}(\mathrm{n}=14$; $7.7 \%$ ). Median OS was calculated at 36 months for T2 (SE: 9.809), 38 months for T3 (SE: 6.341), 21 months for T4a (SE: 1.32), and 13 months for T4b stage (SE: 2.806), with a statistically significant difference $(\mathrm{P}=0.041$; Figure $2 \mathrm{~A})$.

When the $\mathrm{N}$ stage distribution of the patients was evaluated, N0 ( $\mathrm{n}=71 ; 39.5 \%), \mathrm{N} 1(\mathrm{n}=42 ; 23.3 \%), \mathrm{N} 2$ $(\mathrm{n}=50 ; 27.8 \%)$, and $\mathrm{N} 3(\mathrm{n}=17 ; 19.4 \%)$ were treated. The median OS was calculated at 40 months for N0 (SE: 14.66), 37 months for N1 (SE: 16.977), 22 months for N2 (SE: 4.922), and 25 months for N3 (SE: 6.137), with a statistically significant difference $(\mathrm{P}=0.033$; Figure 2B).

When the TNM stage distribution at the time of diagnosis was examined, stages II $(\mathrm{n}=66 ; 36.6 \%)$, IIIa $(\mathrm{n}=42 ; 23.9 \%)$, IIIb $(\mathrm{n}=28 ; 15.5 \%)$, and IIIc $(\mathrm{n}=44$; $24.5 \%$ ) were treated. The median OS was 69 months for stage II, 23 months for stage IIIa (SE: 19.179), 26 months for stage IIIb (SE: 5.360), and 19 months for stage IIIc (SE: 2.815), with a statistically significant difference $(\mathrm{P}=0.00$; Figure $2 \mathrm{C})$.

Based on the examination of the oncologic modality of EC cases included in the present study, 45 (25\%), $33(18.3 \%), 59(32.8 \%)$, and $43(23.9 \%)$ patients received definitive RT, postoperative adjuvant CRT/RT, preoperative CRT/RT, and definitive CRT, respectively. In other words, the patients underwent RT at a different phase of treatment, and 157 subjects $(87.2 \%)$ received RT as a primary treatment. Furthermore, 18 cases $(10 \%)$ received RT postoperatively, and 5 subjects (2.8\%) underwent RT after recurrence.

The cases receiving definitive RT or definitive CRT were nonsurgical candidates. Median OS was reported as 32 months in subjects undergoing

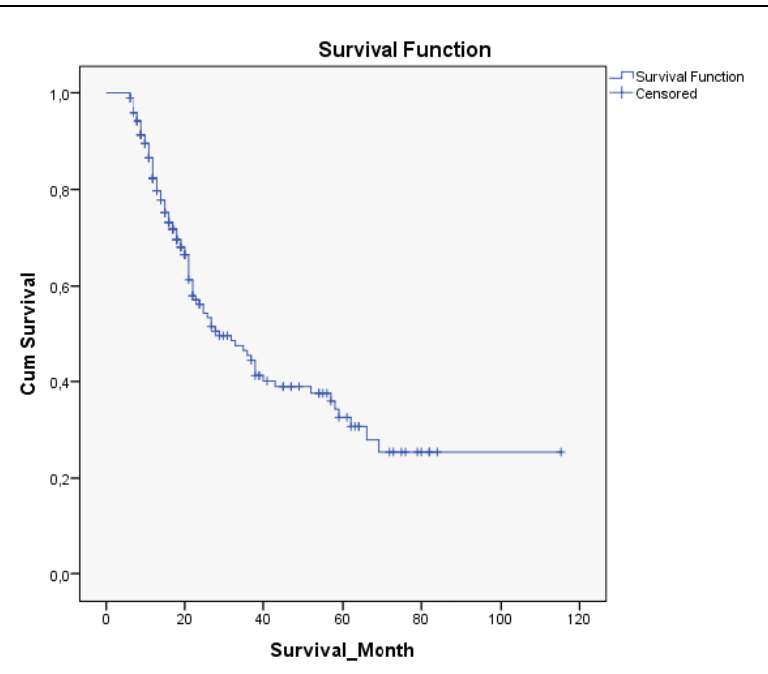

Figure 1. Overall survival curves of 180 patients treated for esophageal cancer 

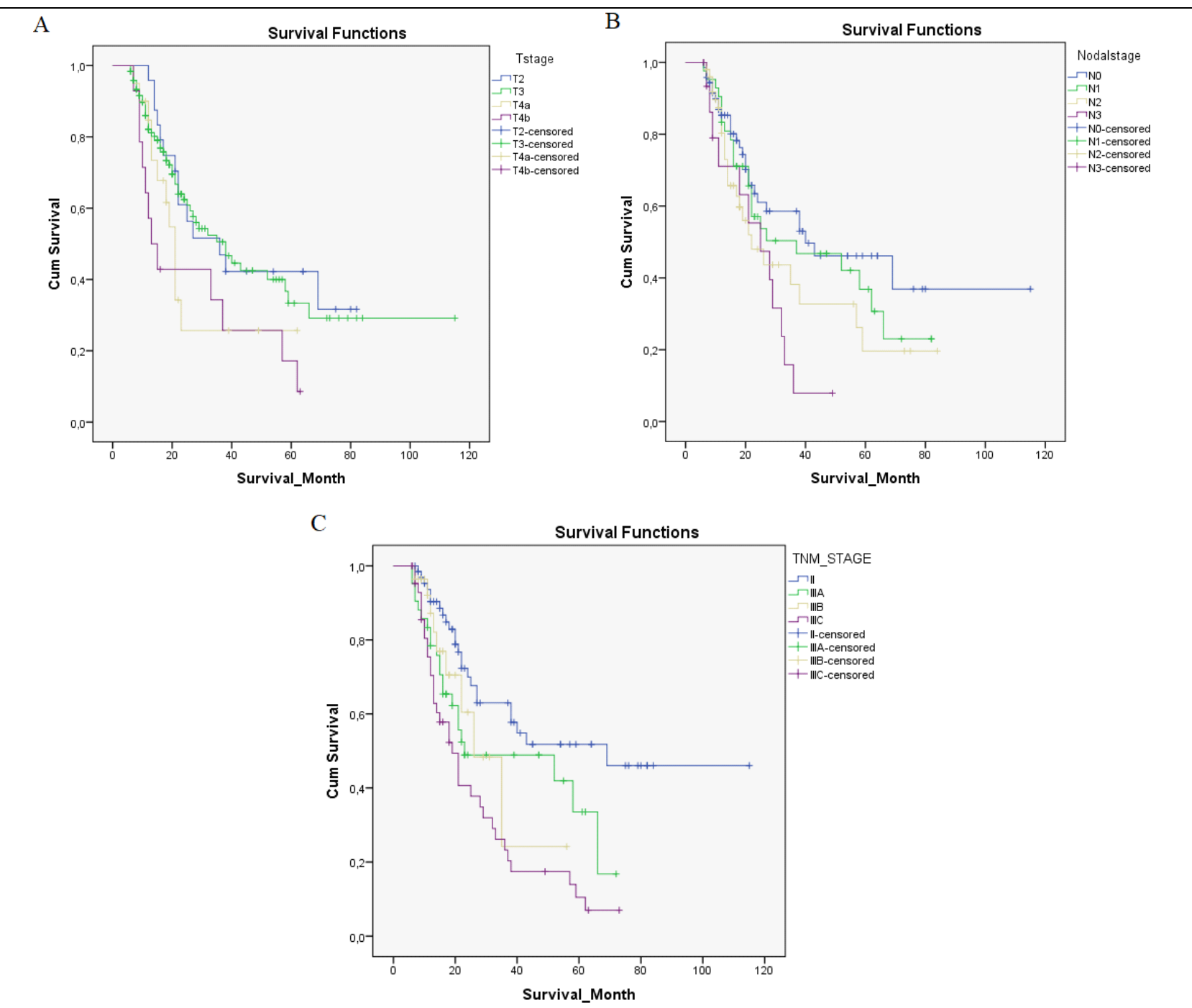

Figure 2. Overall survival curves of 180 patients treated for esophageal cancer based on A) T stage groups, B) N stage groups, and C) tumor, nodes, and metastases (TNM) stage groups

definitive RT (SE: 5.837), 25 months in the postoperative adjuvant CRT/RT group (SE: 8.677), 38 months in the preoperative CRT/RT group (SE: 0.685), and 21 months in the definitive CRT group (SE: 2.05), but with no statistically significant difference $(\mathrm{P}=0.387)$. However, when the groups receiving concomitant $\mathrm{CT}$ were compared to the group not receiving concomitant $\mathrm{CT}$, the median OS was calculated at 43 and 22 months, respectively, with a statistically significant difference $(\mathrm{P}=0.001$; Figure 3). Conventional and conformal RT were applied for $53.4 \%(n=96)$ and $46.6 \%(n=84)$ of the study subjects, respectively.

Median OS for age groups was calculated at 40 (SE: 17.662), 35 (SE: 5.619), and 26 (SE: 4.26) months, respectively, with no statistically significant difference ( $\mathrm{P}=0.438)$. In addition, 42.8\% $(\mathrm{n}=77)$ and $57.2 \%(\mathrm{n}=103)$ of the patients were male and female, respectively. The median OS was calculated for the male and female groups at 26 (SE: 3.27) and 38

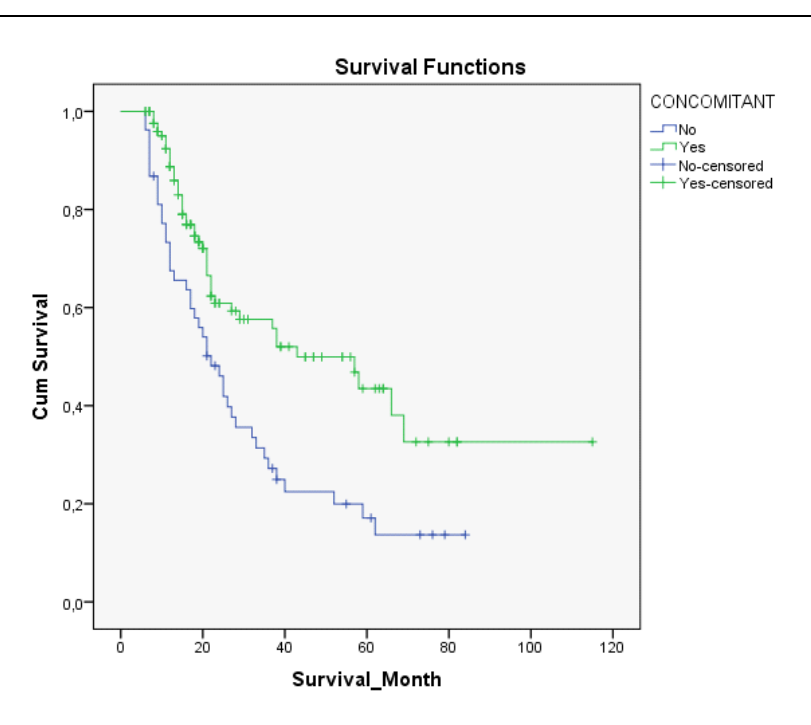

Figure 3. Overall survival curves of 180 patients treated for esophageal cancer based on concomitant chemoradiation 
(SE: 8.025) months, respectively, with no statistically significant difference $(\mathrm{P}=0.105)$. In the evaluation according to histopathological diagnosis, ESCC was observed to be subtype in $86.6 \%$ of cases and EAC in $13.4 \%$ of the subjects. The median OS for ESCC and EAC was 32 (SE: 5.714) and 29 months (SE: 8.041), respectively, with no statistically significant difference ( $\mathrm{P}=0.382)$.

Tumor location was evaluated using endoscopic data and positron emission tomography-computed tomography. Upper, middle, and lower thoracic tumors were diagnosed in 5\% (n=9), 28.4\% ( $\mathrm{n}=51)$, and $66.6 \%(n=120)$ of the patients, respectively. According to the location of the tumor, median OS for the upper, middle, and lower thoracic tumors was calculated at 59, 32, and 27 months, respectively, with no statistically significant difference $(\mathrm{P}=0.449)$. According to ECOG performance status, 51 (28.4\%), $95(52.8 \%)$, and $34(18.8 \%)$ patients had ECOG 0, ECOG 1, and ECOG 2, with median OS calculated at 35, 33 , and 25 months, respectively, with no statistically significant difference $(\mathrm{P}=0.247)$. Table 2 shows the

\begin{tabular}{|c|c|c|c|c|c|}
\hline \multirow{2}{*}{$\begin{array}{l}\text { Analysis data } \\
\text { Variable }\end{array}$} & \multirow{2}{*}{$\begin{array}{c}\text { Estimated median survival } \\
\text { (n) }\end{array}$} & \multirow{2}{*}{ SD } & \multicolumn{2}{|c|}{$95 \% \mathrm{CI}$} & \multirow{2}{*}{ P-value } \\
\hline & & & Lower bound & Upper bound & \\
\hline Overall & 29 & 4.859 & 19.477 & 38.523 & \\
\hline Age group (year) & & & & & 0.438 \\
\hline$\leq 40$ & 40 & 17.662 & 5.383 & 74.617 & \\
\hline $41-60$ & 35 & 5.619 & 23.986 & 46.014 & \\
\hline$>60$ & 26 & 4.26 & 17.65 & 34.35 & \\
\hline Gender & & & & & 0.105 \\
\hline Male & 26 & 3.27 & 19.59 & 32.41 & \\
\hline Female & 38 & 8.025 & 22.271 & 53.729 & \\
\hline Pathology & & & & & 0.382 \\
\hline SCC & 32 & 5.714 & 20.8 & 43.2 & \\
\hline Non-SCC & 29 & 8.041 & 13.24 & 44.76 & \\
\hline Anatomical localization & & & & & 0.449 \\
\hline Proximal & 59 & - & - & - & \\
\hline Mid & 32 & 8.085 & 16.153 & 47.847 & \\
\hline Distal & 27 & 5.188 & 16.831 & 37.169 & \\
\hline $\mathbf{T}$ & & & & & 0.041 \\
\hline $\mathrm{T} 2$ & 36 & 9.809 & 16.774 & 55.226 & \\
\hline T3 & 38 & 6.341 & 25.572 & 50.428 & \\
\hline $\mathrm{T} 4 \mathrm{a}$ & 21 & 1.32 & 18.413 & 23.587 & \\
\hline $\mathrm{T} 4 \mathrm{~b}$ & 13 & 2.806 & 7.5 & 18.5 & \\
\hline $\mathbf{N}$ & & & & & 0.033 \\
\hline No & 40 & 14.66 & 11.267 & 68.733 & \\
\hline N1 & 37 & 16.977 & 3.725 & 70.275 & \\
\hline $\mathrm{N} 2$ & 22 & 4.922 & 12.354 & 31.646 & \\
\hline N3 & 25 & 6.137 & 12.971 & 37.029 & \\
\hline Stage & & & & & 0.00 \\
\hline II & 69 & - & - & - & \\
\hline IIIA & 23 & 19.179 & 0.0 & 60.591 & \\
\hline IIIB & 26 & 5.360 & 15.494 & 36.506 & \\
\hline IIIC & 19 & 2.815 & 13.482 & 24.518 & \\
\hline Treatment & & & & & 0.387 \\
\hline $\begin{array}{l}\text { Definitive RT (non- } \\
\text { operation) }\end{array}$ & 32 & 5.837 & 20.559 & 43.441 & \\
\hline $\begin{array}{l}\text { Postoperative adjuvant } \\
\text { CRT/RT }\end{array}$ & 25 & 8.677 & 7.994 & 42.006 & \\
\hline Preoperative CRT/RT & 38 & 0.685 & 36.658 & 39.342 & \\
\hline $\begin{array}{l}\text { Definitive CRT (non- } \\
\text { operation) }\end{array}$ & 21 & 2.05 & 16.982 & 25.018 & \\
\hline RT & & & & & 0.907 \\
\hline Primer & 28 & 6.059 & 16.125 & 39.875 & \\
\hline Postoperative & 27 & 3.89 & 19.375 & 34.625 & \\
\hline After recurrence & 59 & 20.813 & 18.206 & 99.794 & \\
\hline Concomitant CT & & & & & 0.001 \\
\hline No & 22 & 2.959 & 16.201 & 27.799 & \\
\hline Yes & 43 & 10.16 & 23.086 & 62.914 & \\
\hline ECOG & & & & & 0.247 \\
\hline Fully active & 35 & 15.704 & 4.221 & 65.779 & \\
\hline Restricted activity & 33 & 6.583 & 20.098 & 45.902 & \\
\hline Restricted work activity & 25 & 5.425 & 13.366 & 35.634 & \\
\hline
\end{tabular}

SD: Standard deviation; CI: Confidence interval; SCC: Squamous cell carcinoma; AJCC: American Joint Committee on Cancer; RT: Radiotherapy; CT: Chemotherapy; CRT: Chemoradiotherapy; ECOG: Eastern Cooperative Oncology Group 


\begin{tabular}{|c|c|c|c|c|}
\hline & \multirow{2}{*}{ P-value } & \multirow{2}{*}{ HR } & \multicolumn{2}{|c|}{$95 \% \mathrm{CI}$} \\
\hline & & & Lower bound & Upper bound \\
\hline TNM staging & 0.001 & 2.265 & 1.409 & 3.641 \\
\hline Concommittant CRT & 0.002 & 0.513 & 0.337 & 0.779 \\
\hline
\end{tabular}

results of the univariate analysis of the patients.

Cox regression test was used for multivariate analysis. In multivariate analysis, concomitant CRT (95\% CI: 0.337-0.779) and TNM stage (95\% CI:

\section{Discussion}

According to the 2018 data of global cancer statistics, EC accounts for $3.2 \%$ of all cancers and $5.3 \%$ of GI cancers. In addition, $5.3 \%$ of all cancer mortalities are EC-related (1). The rate of EAC has been rapidly increasing in the last 40 years in Western countries, especially in North America and Europe. This increase increases the male-female ratio (MFR) up to 9:1 depending on male superiority (16). According to the global cancer statistics data, the MFR was calculated to be 1.851 worldwide (17). Moreover, the gender ratio was calculated at 0.7 . In the present study, the specific treatment group was evaluated not indicating the actual MFR of the region.

The incidence of EAC is increasing in Western countries and is 6-10 times higher in male patients than that reported for female cases; this rate is 2-3 times higher in ESCC (18). Several phase III randomized controlled trials investigated the indication of preoperative CRT and role of RT in locally advanced EC patients. Walsh et al. carried out a study on 113 patients with EAC in which the subjects were randomized to surgical and preoperative CRT. The median OS was only 11 months in the surgical arm and 16 months in multimodal treatment. Moreover, 1 and 3 years of OS in patients receiving multimodal therapy increased from $32 \%$ to $52 \%$ and $6 \%$ to $44 \%$, respectively $(\mathrm{P}=0.01)$ (19).

In a European Organisation for Research and Treatment of Cancer phase III randomized controlled study conducted by Bosset JF et al., 282 subjects with a histopathological diagnosis of ESCC were randomized to surgical and preoperative CRT. The patients underwent treatment with two cycles of cisplatin and 37 Gy RT in 10 fractions. At the end of the study, no significant difference was observed between the two arms in median OS (18.6 months); nevertheless, disease-free survival $(\mathrm{P}=0.003)$, curative resection rate $(\mathrm{P}=0.017)$, and cancer mortality $(\mathrm{P}=0.002)$ were better, higher, and lower in the preoperative CRT arm, respectively (20).

In another phase III randomized trial carried out by Urba et al., 100 subjects with EAC (75\%) and ESCC
1.409-3.641) were observed to be statistically significant as independent predictors of mortality $(\mathrm{P}=$ 0.002 and $\mathrm{P}=0.001$, respectively). Table 3 tabulates the results of multivariate analysis of the patients.

(25\%) histopathology were randomized to surgical and preoperative CRT. Concomitant CT was administered with cisplatin, vinblastine, and fluorouracil (5-FU), and hyperfractionated RT was performed twice daily with a fraction dose of $1.5 \mathrm{~Gy}$ for a total of $45 \mathrm{~Gy}$. Local recurrence reduced and 3-year OS increased from $15 \%$ to $30 \%$ with neoadjuvant CT; nonetheless, there was no statistically significant difference (21).

Two major phase III randomized controlled trials investigating the utility of definitive CRT have been planned by the Radiation Therapy Oncology Group (RTOG). In the first study conducted by Cooper et al. (RTOG 85-01), the participants were randomized to RT and CRT with combined-modality therapy arms. In the combined-modality therapy arm $(n=134)$, the patients received 50 Gy RT in 25 fractions for 5 weeks in addition to intravenous cisplatin and 5-FU by continuous infusion, compared to 64 Gy in 32 fractions for 6.4 weeks in RT only arm. Based on the long-term findings of the aforementioned study, the combination treatment significantly improved OS in comparison to RT alone. Five-year OS was reported as $14 \%$ in the combined arm; nevertheless, severe acute toxicity was observed in the combined arm (10\% vs. $2 \%)(10)$.

In another important phase III trial performed by Minsky BD et al. (INT 0123-RTOG 94-05), 236 nonmetastatic patients were randomized into highdose (64.8 Gy) and standard-dose (50.4 Gy) RT arms. The CT consisted of four cycles of cisplatin plus 5-FU in both arms. The study was closed due to more treatment-related mortalities in the high-dose RT arm. There was no statistically significant difference between the two arms regarding median OS (13 and 18 months) and 2-year OS (31\% and 40\%). According to the findings of the aforementioned study, the standard radiation dose for cases undergoing treatment with concomitant 5-FU and cisplatin was determined at 50.4 Gy (22).

In a randomized study carried out by Van Hagen et al. (Chemoradiotherapy for Oesophageal Cancer Followed by Surgery Study group), 366 patients with locally advanced EC (ESCC [25\%] and EAC [75\%]) were randomized to surgery arm and preoperative CRT followed by surgery arm. The survival and 
resectability of preoperative CRT were investigated in the aforementioned study. The CT was performed in addition to carboplatin plus paclitaxel and RT (41.4 Gy in 23 fractions; 5 days per week). Median OS was reported as 49.4 months in the surgery arm followed by preoperative CRT and 24 months in the surgery arm alone (95\% CI: 0.495-0.871; $\mathrm{P}=0.003$ ). Therefore, preoperative CRT resulted in a significant improvement in OS (23).

\section{Conclusion}

The results of the current study revealed that there were important prognostic factors with effects on the survival in the treatment of EC patients in the Eastern Anatolia region of Turkey as an endemic area for upper GI tract tumors. Long-term survival is possible with an early diagnosis of patients. The addition of CT to RT with combined-modality therapy was demonstrated as an independent prognostic factor of survival in patients with locally advanced EC. Furthermore, in multivariate analysis, TNM stage and concomitant CRT were shown to be independent prognostic factors of mortality. On the other hand, based on the results, it was concluded that combinedmodality therapy increases the survival of patients with ESCC or EAC.

\section{Acknowledgments}

None declared.

\section{Footnotes}

Authors' Contribution: Hamit Başaran was the corresponding author and evaluated and wrote the manuscript. Deniz Arslan and Okan özdemir created the database. Menekşe Turna drafted the abstract. Yılmaz Özdemir and Sibel Karaca prepared the patients' demographic data and carried out statistical analyses. Hamit Başaran and Asuman Önol Mirik drafted the methods section, prepared the figures, revised the initial draft of the manuscript, and approved the final version of the manuscript. All the authors read and approved the final manuscript.

Conflict of Interests: The authors declare that there is no conflict of interest.

Ethical Approval: The ethical approval of this retrospective single-center study was obtained from the Ethics Committees of Health Science University, Regional Training and Research Hospital in Erzurum, Turkey. The study procedures were performed under the ethical principles of the Institutional and/or National Research Committee and in accordance with the 1964 Helsinki Declaration and its later amendments or comparable ethical standards. All the study subjects gave informed consent.

Funding/Support: None declared.
Financial Disclosure: None declared. Informed Consent: Not applicable.

\section{References}

1. Siegel RL, Miller KD, Jemal A. Cancer statistics, 2019. CA Cancer J Clin. 2019;69(1):7-34. doi: 10.3322/caac.21551. [PubMed: 30620402].

2. Bray F, Ferlay J, Soerjomataram I, Siegel RL, Torre LA, Jemal A. Global cancer statistics 2018: GLOBOCAN estimates of incidence and mortality worldwide for 36 cancers in 185 countries. CA Cancer J Clin. 2018;68(6):394-424. doi: 10.3322/caac.21492. [PubMed: 30207593].

3. Shridhar R, Imani-Shikhabadi R, Davis B, Streeter OA, Thomas CR Jr. Curative treatment of esophageal cancer; an evidenced based review. J Gastrointest Cancer. 2013;44(4):375-84. doi: 10.1007/s12029-013-9511-9. [PubMed: 23824628].

4. Shridhar R, Almhanna K, Meredith KL, Biagioli MC, Chuong MD, Cruz A, et al. Radiation therapy and esophageal cancer. Cancer Control. 2013;20(2):97-110. doi: 10.1177/107327481302 000203 .

5. Ferlay J, Soerjomataram I, Dikshit R, Eser S, Mathers C, Rebelo M, et al. Cancer incidence and mortality worldwide: sources, methods and major patterns in GLOBOCAN 2012. Int J Cancer. 2015;136(5):E359-86. doi: 10.1002/ijc.29210. [PubMed: $25220842]$

6. Koca T, Arslan D, Basaran H, Cerkesli AK, Tastekin D, Sezen D, et al. Dietary and demographical risk factors for oesophageal squamous cell carcinoma in the Eastern Anatolian region of Turkey where upper gastrointestinal cancers are endemic. Asian Pac J Cancer Prev. 2015;16(5):1913-7. doi: 10.7314/apjcp.2015.16.5.1913. [PubMed: 25773844].

7. Mathieu LN, Kanarek NF, Tsai HL, Rudin CM, Brock MV. Age and sex differences in the incidence of esophageal adenocarcinoma: results from the surveillance, epidemiology, and end results (SEER) registry (1973-2008). Dis Esophagus. 2014;27(8):757-63. doi: 10.1111/dote.12147. [PubMed: 24118313].

8. el-Serag HB. The epidemic of esophageal adenocarcinoma. Gastroenterol Clin North Am. 2002;31(2):421-40. doi: 10.1016/s0889-8553(02)00016-x. [PubMed: 12134611].

9. Javle M, Ailawadhi S, Yang GY, Nwogu CE, Schiff MD, Nava HR Palliation of malignant dysphagia in esophageal cancer: a literature-based review. J Support Oncol. 2006;4(8):365-73. [PubMed: 17004508].

10. Cooper JS, Guo MD, Herskovic A, Macdonald JS, Martenson JA Jr, Al-Sarraf M, et al. Chemoradiotherapy of locally advanced esophageal cancer: long-term follow-up of a prospective randomized trial (RTOG 85-01). Radiation Therapy Oncology Group. JAMA. 1999;281(17):1623-7. doi: 10.1001/jama.281.17. 1623. [PubMed: 10235156].

11. Cunningham D, Allum WH, Stenning SP, Thompson JN, Van de Velde CJ, Nicolson M, et al. Perioperative chemotherapy versus surgery alone for resectable gastroesophageal cancer. $N$ Engl $J$ Med. 2006;355(1):11-20. doi: 10.1056/NEJMoa055531. [PubMed: 16822992].

12. Macdonald JS, Smalley SR, Benedetti J, Hundahl SA, Estes NC, Stemmermann GN, et al. Chemoradiotherapy after surgery compared with surgery alone for adenocarcinoma of the stomach or gastroesophageal junction. $N$ Engl J Med. 2001;345(10):72530. doi: 10.1056/NEJMoa010187. [PubMed: 11547741].

13. Fokas E, Rodel C. Definitive, preoperative, and palliative radiation therapy of esophageal cancer. Viszeralmedizin. 2015;31(5):347-53. doi: 10.1159/000440638. [PubMed: 26989391].

14. Mariette C, Dahan L, Mornex F, Maillard E, Thomas PA, Meunier $B$, et al. Surgery alone versus chemoradiotherapy followed by surgery for stage I and II esophageal cancer: final analysis of randomized controlled phase III trial FFCD 9901. J Clin Oncol. 2014;32(23):2416-22. doi: 10.1200/JC0.2013.53.6532. [PubMed: 24982463].

15. Gao XS, Qiao X, Wu F, Cao L, Meng X, Dong Z, et al. Pathological 
analysis of clinical target volume margin for radiotherapy in patients with esophageal and gastroesophageal junction carcinoma. Int J Radiat Oncol Biol Phys. 2007;67(2):389-96. doi: 10.1016/j.ijrobp.2006.09.015. [PubMed: 17236963].

16. Xie SH, Lagergren J. The male predominance in esophageal adenocarcinoma. Clin Gastroenterol Hepatol. 2016;14(3):33847.e1. doi: 10.1016/j.cgh.2015.10.005. [PubMed: 26484704].

17. Jemal A, Bray F, Center MM, Ferlay J, Ward E, Forman D. Global cancer statistics. CA Cancer J Clin. 2011;61(2):69-90. doi: 10.3322/caac.20107. [PubMed: 21296855].

18. Vizcaino AP, Moreno V, Lambert R, Parkin DM. Time trends incidence of both major histologic types of esophageal carcinomas in selected countries, 1973-1995. Int J Cancer. 2002;99(6):860-8. doi: 10.1002/ijc.10427. [PubMed: 12115489].

19. Walsh TN, Noonan N, Hollywood D, Kelly A, Keeling N, Hennessy TP. A comparison of multimodal therapy and surgery for esophageal adenocarcinoma. $N$ Engl J Med. 1996;335(7):462-7. doi: 10.1056/NEJM199608153350702. [PubMed: 8672151].

20. Bosset JF, Gignoux M, Triboulet JP, Tiret E, Mantion G, Elias D, et al. Chemoradiotherapy followed by surgery compared with surgery alone in squamous-cell cancer of the esophagus. $N$ Engl J Med. 1997;337(3):161-7. doi: 10.1056/NEJM199707 173370304. [PubMed: 9219702].

21. Urba SG, Orringer MB, Turrisi A, Iannettoni M, Forastiere A, Strawderman M. Randomized trial of preoperative chemoradiation versus surgery alone in patients with locoregional esophageal carcinoma. J Clin Oncol. 2001; 19(2):305-13. doi: 10.1200/JC0.2001.19.2.305. [PubMed: 11208820].

22. Minsky BD, Pajak TF, Ginsberg RJ, Pisansky TM, Martenson J, Komaki R, et al. INT 0123 (Radiation Therapy Oncology Group 94-05) phase III trial of combined-modality therapy for esophageal cancer: high-dose versus standard-dose radiation therapy. J Clin Oncol. 2002;20(5):1167-74. doi: 10.1200/JC0.2002.20.5.1167. [PubMed: 11870157].

23. van Hagen P, Hulshof MC, van Lanschot JJ, Steyerberg EW, van Berge Henegouwen MI, Wijnhoven BP, et al. Preoperative chemoradiotherapy for esophageal or junctional cancer. $N$ Engl J Med. 2012;366(22):2074-84. doi: 10.1056/NEJMoa1112088. [PubMed: 22646630]. 